\title{
Theoretical Thinking vs Theorization in Translation
}

\author{
Mine Yazıc1 \\ Department of Translation Studies, Edebiyat Fakültesi, Istanbul University, Turkey
}

Received: 12-05-2015

doi:10.7575/aiac.ijclts.v.3n.3p.70
Accepted: 19-07- 2015

Published: 31-07- 2015

\begin{abstract}
Since translation concerns all disciplines, we may ask whether it is possible to conduct theoretical research peculiar to translations, or to what extent theoretical thinking is possible in a field of study which has a nexus of complex relations with other disciplines. We can answer these questions if we understand why we have a recourse to theorization in translation. Since the defining feature of theory as a complex set of relations overlaps with the concept of translation, they both involve complex mental procedures. Mental procedures in both actions operate similarly; that is to say, both theorists and translators draw up analogies between similar cases in order to define, classify and categorize the components of complexity. In theorization these procedures are called "abstraction" and "simplification"; whereas in translation studies, we call it "deverbalization". It means stripping the linguistic form of a text, or a document so as to understand the sense of it (Gile 2003:47). Accordingly, we can reach such a conclusion that both translation and theorization follow the same logical sequence in understanding and overcoming the complexity. In the light of these introductory remarks the present study discusses the concept of theory, and theorization both in translation and translation studies so as to draw up similarities and divergencies between translation theory and translation practice.
\end{abstract}

Keywords: Theoretical Thinking, Theorization, Translation Criticism, Meta-level thinking

\section{Theory and Theorizing}

The concept "theory" is culture-bound; it gains new senses according to the culture in which it is used in just the same way as the concept of translation which gains new senses as a fact of target culture. Etymologically, the word "theory" is composed of the Greek words "thēa" (view) + "horon" (see ).It means "looking at a view". Whereas, the Arabic equivalent of the word "theory" in Ottoman Turkish is "nazariye", which means "looking, or glancing in, or at a thing" in the Redhouse Dictionary from Turkish to English (1968). We can conclude that "nazariye" corresponds to the Greek term "theory" etymologically. However, terms gain new senses according to the cultures they enter and their meanings may change in the course of time. For example, during the reign of Ottoman Empire, the loan word "nazariye" preserves the same sense as in Arabic since the Ottoman Empire adopted Arabic script in official correspondence. However, "nazariye" in Ottoman Turkish was replaced with the Greek loan term "teori" with the impact of Westernization up till 1970s. However, after 1970s the new term "kuram" was used as a result of linguistic policies advocating "linguistic purism". Theory, or its newly derived equivalent "Kuram" derives from the etymological root of the verb "kurmak", which means "establish, construct or found" in Modern Turkish, and the suffix "-am"which changes the infinitive form of the word into a noun.. In fact, the adoption of the new word "kuram" also signals the expectations of the society from theorization. The root of the verbal noun "kurmak" implies constructing something "concrete"; thereby, expecting something concrete serving for pragmatic ends. Accordingly, we can claim when the term "kuram" was derived from the infinitive "kurmak" in 1980s, and enter the common language use with the impact of "purism" in Turkish language, theory was assumed to act as a guide to found or establish something. It is for this reason that theory has been thought to answer the question "how?" for a long period of time in Turkey as opposed to the universally acknowledged conception that the main goal of theory is to observe and think on the underlying reasons of a complex situation and hypothesize new relations, or possibilities for further research. Today in Turkish Dictionary of Turkish Language Society, which is an official site of Turkish language, it is defined "as a whole and systematic collection of fundamental rules or, codes of a discipline "(http://www.tdk.gov.tr/). This definition is closer to the original sense of the term "theory" and emphasizes "meta-level thinking" in theorization as opposed to the past expectations concerning pragmatic ends in theoretical thinking. It may have been for this reason that in the first entry of the terminological dictionary of philosophy from Modern Turkish into Ottoman Turkish, English, German and French, the term "kuram"(theory) was defined as " absolute knowledge serving neither for pragmatic ends, nor for the ends of applied field"(TDK, 1975. This implies Turkish philosophers' past concern about the misusage of the term "kuram" as something serving for pragmatic ends. Furthermore, it draws up the demarcation line between theory and applied field to erase the past misconception affiliating theoretical field to the applied field with the hope of gaining pragmatic ends from theorization.

This brief etymological discussion in Turkish language shows what changes a term undergo in the course of time in face of international interactions, or ideological changes which nations become subject to. Undoubtedly, these changes concerning the terms change our perception of the world. With the consolidation of academic disciplines and fast 
dissemination of knowledge through information technologies as well as the language as a living organism, the established terms becomes subject to changes or transformations. On the other hand, in the course of time the definition of the term "theory" which limits the borders of the definition to "observation", and "reasoning" without seeking any pragmatic ends, has also extended and changed. If we set out from the "a priori" that every action has a goal we can claim that theorization may have pragmatic ends alongside observing, and reasoning. That is to say, we try to observe, understand and interpret the existing situation in order to elicit new contingencies awaiting for us. To put it another way, the function of theorization is not just "reflection" without any "pragmatic ends". On the contrary, systematizing the complex phenomena and eliciting laws or rules from it denotes the knowledge acquired from theorization can be monitored, or filtered in such a way as to serve for the pragmatic ends of the applied field. Accordingly, we can claim that the sense of the Arabic loan term "nazariye" Arabic, or the Greek loan term "teori" has expanded and undergone changes on the spatio- temporal axis today. After this brief etymological account of the term theory in Turkish, we can enlist the stages of conducting a research as follows:

1. Observation: It means observing the events, facts or objects in the world.

2. Abstraction: It means visualizing, drawing up mental picture stripping of linguistic form, or mental reflection of an object or word.

3. Definition: It means defining and demarcating the borders of the discipline.

4. Explanation: It means identification of relations between the facts and setting up correlations between them. Undoubtedly, it is based on "analytical thinking".

5. Simplification: It means to simplify the complex situation to understand and systematize a complex situation. We may also call it "filtering", which may help us to focus on the main problems and to disclose systemic relations.

6. Classification: It helps to subsume the problems under the categories, or sub-categories.

7. Reasoning: It means to understand the complex relations and draw logical inferences from the complex relations between them. In fact, it helps to enlist the problems in algorithmic flow.

8. Rationalization: It means justification of the relationship between causes and effects. It is closely related with "causality". In other terms, it is a way of drawing up a causal nexus or network between complex relations.

9. Systematization: It means to put the data, or findings into order in such a way as to form a "system" based on the knowledge obtained from observation, or data.

10. Encoding: It means to constitute or develop a specific terminology or jargon concerning the problem.

11. Sharing: It means sharing the new findings with those who are concerned with the same problems to discuss the different aspects of the complexity.

12. Testing: It means testing the theory in different frameworks of research.

13. Legitimizing: It means drawing up rules, or laws if the same findings obtained from the research conducted in different frameworks.

The above-mentioned listing in theorization proceeds in a hierarchical order. Besides, they are amalgamated with each other in such a way as to submit a solution to a problem. The laws and rules concerning the complexity, or the problem can be elicited only if the researcher proceeds without skipping any of the stages enlisted above. However, in proceeding from one step to another the researcher should set up correlations between them. For example, abstraction and definition have two functions: while "abstraction" is related with producing new ideas out of complex relations which leads to "creativity" fostered by "divergent thinking, "definition" which is related with "selecting" and " sorting out" the options resulting from divergent thinking serves for demarcating and defining the borders of a specific problem. Accordingly, we can claim while "abstraction" takes place in uncontrolled mental space, "definition" takes place in controlled mental space to make the complexity or the problem intelligible to others. Since "definition" serves for the identification of the problem, we may also call this stage definition of problem, or "problematization". Without "problematization" or without defining the problem we cannot set out research. By defining the problem, we draw up the borders of the research and identify our object of study. It is only after the stage of the definition of the problem can we start selecting and sorting out the data to form our corpus of study to justify our claims concerning the problem.

Undoubtedly, "problematization" and "justification" are also interrelated with each other since they constitute the logical grounds for "theorization", and require "systematization" of data in such a way as to reach findings concerning the main problem. However, during the process of systematization we simplify the complex phenomena in real life to draw up a mental replica of it. That is to say, we simplify it to understand and explain the complexity. It is only after the findings are explained and justified in a systematic way that we can elicit the laws and rules, and reach the final stage called "legitimization" which provides scientific grounds for the testability of the theory in which researchers can test their claims.

Theorization continues as long as the scholars studying on the several aspects of the same complexity discuss and test their claims within the framework of the theory. This means theorization is a means of developing "scientific jargon", which is an evidence of the legitimacy of a discipline as well as professionalism. By this way, researchers sharing the same field of study can maintain correspondence with each other referring to the same scientific jargon. In short, we can claim theorization lays the foundations of a discipline, and it gains its autonomy and consolidates itself as long as it maintains theorization in its own scientific jargon. This proves close relationship between language and theorization since disciplines can emerge only if they can develop their own scientific jargon as a result of theorization. In other words, scientific jargon can be assumed as a scientific evidence of the autonomy and testifies the legitimacy of a discipline. Accordingly, we can acknowledge "theorization" as a way of intralingual translation, which involves 
"complexity", "reduction" or "simplification" just as in interlingual translation, or in translation proper (Salevsky 2011:268).

\section{Translation Activity and Theorization}

Starting translation theory with the question "what is translation?" will disclose the relationship between translation activity and theorization. The Latin root of the word "trans-"means transfer from one place to another. In Ottoman Turkish it was translated as "Terceme", whereas in modern Turkish we call it "çeviri" which literally means "turn", "change or transform". In Russian, the term "perevód" is used in the same sense as interlingual translation; In Chinese the equivalent of translation is "fanyi", which means "exchange"; In Sanskrit and Hindi languages, they use the term "rupantar' to denote transformation, or rewriting; They also use the term 'anuvade', which means " saying later. Meanwhile new terms appear to replace with the term "translation". For example, the "transcreation" in place of translation stresses upon the creative aspect of translation. The other new term is "cannibalism", which is used as a reaction against the policy of super powers that manipulate translation as a means of hegemony. From these definitions, one concludes that the sense of translation changes not only according to each culture, or according to each field of study, but also in the course of time. While some cultures emphasized the spatial aspect of translation, the others stress on the temporal aspect of it as in the example of the Sanskrit term "anuvid"; Or, in some languages as in English, or French, the term may cover both spatial and temporal axis. Since the correlation between the signifier and signified is arbitrary, the semantic load of the signifier expands along with the advances recorded in the theoretical field. For example, during the reign of the Ottomans, the term Terceme was classified into four groups. Saliha Paker quoted them from the literary historian Agah Sırrı Levend's remarkable work titled Türk Edebiyatı Tarihi, and enlisted them as "literal", "faithful", literary translations involving "the transfer of subject matter", and "expanded literary translations" (Paker 2002:124) Within this framework, Paker states that the demarcation between the last two options concerning the definitions of the literary translation is imprecise. However, when we studied the Republican Age, we saw that the definition of terms became more precise. For example, in "the First Turkish Publications Congress" in 1939 the term "the original" was distinguished from term "terceme" (translation) within the framework of copyrights as follows:

We concluded that translation and original are not the same. Original is the product of great labour of man. However, Terceme is transferring the original from one space to another through using foreign language skills. (Birinci Türk Neşriyat Kongresi 1939: 77)

There are two points here: First, translation was defined as the transfer of signs; second is, for the first time, translation was defined within the framework of copyrights. On the one hand, the definition of terceme narrowed down to the literal transfer of the original compared to the exhaustive definitions based on the types of translation during the Ottoman reign. On the other hand, it can be evaluated as the sign of the transition from Islamic Law to Roman Law in the foundation years of Turkish Republic (1923); thereby heralding translation not as an amateurish activity peculiar to literary translation, but as a professional occupation.

Today the term "translation" transcends its borders, and extends to the scientific jargon of other disciplines. To put it another way, today we cannot narrow down the definition of translation to the interlingual and intercultural transfer of knowledge, or to the borders of literary translation. It concerns every field of study and transcends its borders. That is to say, it is used in different senses in different fields of study. For example, in biology it means to "convert (a sequence of nucleotides in messenger RNA) to an amino-acid sequence in a protein or polypeptide during synthesis", whereas in Physics it means "cause (a body) to move so that all its parts travel in the same direction, without rotation or change of shape" (http://www.oxforddictionaries.com/ definition/english/translate). However, in Turkish we do not use the term" translation" neither in physics, nor in biology, or in mathematics. We translate, or explain them intralingually into Turkish, which indicates that the term "translation" has not entered the scientific jargon of neither physics, nor biology. That is to say, there is no Turkish equivalent for the term "translation" in other fields of study as in the scientific jargon of other languages except for Medicine. In short, the discussion I maintained so far on the term "translation" discloses not only the culture-bounded, but also interdisciplinary feature of it.

\subsection{Theory vs Theorizing Translation}

Now if we start with a claim "Translating is theorizing", the concept of "definition" may disclose the correlation between them. If the concept "definition" is the intralingual explanation of a complex phenomenon, then it means "theorization" is a way of intralingual translation. Anthony Pym discusses this issue, and answers the complaints of professionals about the gap between practice and theory as well as their claims concerning theorists not being professional translators as follows:

When Heidegger traces differences between German, Latin and Greek, or when Derrida teases out the various gaps found in translations, who is to say they are not using translation as a way of doing philosophy? (2010:114)

Although I agree with Pym's remarks on the correlation between theory and translation, they differ from each other in terms of object level and meta-level thinking. Translator's object level of thinking leads to focus on the task of translation at micro-level, and is limited to overcoming the problems concerning the translation. On the other hand, theorist's or philosopher's way of theorization requires to produce a new concept, or theoretical framework that is 
testable as a result of inductive reasoning; that is to say, they proceed from the facts and interpret them to see the whole picture. However, translators cannot claim new hypotheses, or theoretical framework at the end of the translation task even if they theorize in translation process to provide linguistic and stylistic coherency of the translation task. It means theorists and professional translators follow different routes of reasoning in reaching their goals even if they share the common denominator "translation" whether it is intralingual as in the example of theorization or interlingual as in translation proper in defining the complexity.

Defining the concept of "translation" in the course of time may prove my claim why theorizing in the course of translation cannot be acknowledged as translation theory.

In Latin, the morpheme "Translatio-"means carried by boat from one shore to the other. In the course of time, the term "translation" was defined through metaphors as follows:

Translating is something like giving a musical performance

A translator is a computer

Translating is giving something a change of dress

To translate is to betray the original

A translation is a struggle between two languages (Chesterman 1997:44)

Whereas, in our culture the following metaphor defining translation is popular:"Translation is like a mistress. If she's faithful then she's not beautiful. If she's beautiful then she's not faithful." However, comparing one thing to another does mean "definition". Moreover, they refer to the translation strategy rather than the definition of it. However, Otto Cade can be claimed to be the first scholar who made the definition of translation proper in 1963 without having recourse to metaphors:

We understand by translation to be any form of transfer of content from the form of one language into the form of another language, and distinguish it from transposition, which is the transfer of content from one form into another within the same language; and from transmutation, the transfer of content from a linguistic form into a non-linguistic one.” (Kade 1963, cited by Salevsky 2011:268)

Here Kade defines "translation proper" by discerning it from "transposition" and "transmutation" and defines "translation" as an act of transfer, or code-switching. (Stolze 2011: 25) Although it was much better than the past definitions of translation through metaphors in term of drawing up the borders of the concept "translation", it can be criticized as being very narrow in comparison with the expanded definitions of translation today. Neither intralingual nor semiotic translation was acknowledged as "translation proper" within the framework of "science of translation". We can evaluate this precise and narrow definition of translation based on transfer competence as an initiative for machine translation. This way of precise and strict sense of definition may have been related to the empirical approach adopted by the scholars in the sixties in scientific research, and perception of translation as a sub category of linguistics; That is to say, the borders between the linguistics and translation was fuzzy. On the other hand, the underlying reason may have been related to the huge demand for the dissemination of knowledge all over the world after the World War II.

When we come to 1990s we see that the notion of translation expanded to such an extent as to cover "rewriting". For example, Andre Lefevere's expanded version of the definition of the term "translation" was as follows:

"the most obviously recognizable type of rewriting, and since it is potentially the most influential because it is able to project the image of an author and/or a (series of) works) in another culture, lifting that and/or those works beyond the boundaries of their culture of origin" (Lefevere 1992:9).

As for today, we come across such terms as "transadaptation" or" transcreation" to replace with the term "translation" to stress upon its discerning feature as creative activity. The moot point here is that most translators resist translation theory in spite of its close correlation with theoretical thinking, or abstract reasoning based on inductive thinking.

The below-mentioned universals of translation disclose the parallelisms between translation and theory:

1. Explicitation: It means to explain what is unfamiliar in target culture in such a way as to disrupt the integrity of the source text.

2. Simplification: It is a tendency to disambiguate and simplify the complexity in source text for the sake of intelligibility

3. Standardization: it is a tendency to convert the unconventional, or extraordinary usage of language peculiar to the author of the source text to standard language.

4. Rephrasing: It is a tendency to change the form or syntax of the source text, but preserving the exact content of the original message in rendering the text. The translator may have a recourse to synonyms or near synonyms, or omissions which may end in shift of expression in translation.

5. Naturalization: it is s a tendency to stress upon the features of target language so as to conform to the literary polysystem of target culture (Baker 1996:183).

6. Formation of a New Code: It means forming a third code apart from textual conventions of both source culture and target culture. That is to say, distribution of author certain features peculiar to translation. 
In fact, all the above-mentioned universals of translation may be acknowledged as theorization since they concern the ways of transfer of "sense" rather than "signs". The translator has recourse to "abstraction", "explanation" or "rationalization" in the same way a theorist does to seize "the sense" of the source text and take translation relevant decisions in translating it. That is to say, the translator undergoes the similar stages in theorization: without abstraction, explanation, simplification or rationalization, s/he cannot conform to the universals of translation since the universals of translation are the defining features, or the borderlines demarcating translations from the originals. Accordingly, s/he compares, processes information for "abstraction" as well as selecting the best option out of many alternatives for "definition", which enables her/him to draw up the whole picture in his/her mind.

When one translates, $\mathrm{s} /$ he takes translatorial decisions in consideration for the initial, preliminary or operational norms to process the source text in such a way as to fulfill a function in target culture. In other words, the translator conducts "translation-oriented text" to abide by the stipulations proposed by the commissioner, or the client. It means that the text belongs to the translator in the course of translation; however, it not belong to her / him when s/he ends his task. It addresses to the readers and fulfills different functions according to expectations of them. On the other hand, theory belongs to the theorist and remains the same whether you refute, or claim a new theory since theory proceeds in "continuity". To put it another way, while translator shapes his decisions according to the goals he sets for each translation task, a theorist has to base her/ his claims, or hypotheses on the previous theories to rationalize her/his new theory. Accordingly, we can claim theorization is different from theorizing translation in terms of "continuity". The notion of "continuity" in theorizing translation means taking "consistent" decisions in the course of translation in consideration for the goals set for in translation-oriented text analysis. That is to say, translator's strategies may change according to each translation task. However, his decisions in translating the text proceed in continuity to provide the coherency of the text. Whereas, from the perspective of theorist, "continuity" refers to maintaining communication or discussion on the same basis and in the same scientific jargon so as to disclose and test different aspects of a complex phenomenon. It is for this reason that we cannot acknowledge theorizing translation as translation theory since translation theory is a systematic study of translations based on translation problems, and it flourishes as long as the debate on translations continues in academic sphere. As for the theorization of translator, her/his mental decisions focuses on "the process", but not on "the product" as in translation theory since translation theory aims to excavate the underlying reasons of a translation problem to draw up laws, rules or norms for prospective translations, or translators. Therefore, retrospective of study on translations in the field of translation theory aims to serve for prospective ends, it fulfills its mission as long as it maintains theoretical discourse on translations in such a way as to develop common scientific jargon between the scholars and the professionals. Accordingly, we can claim scientific jargon is the outcome of theoretical knowledge and the evidence of professionalism even if professional translators resist against translation theory. However, we can claim the resistance against translation theory may originate from the confusion of terms between translation criticism and translation theory

\section{Translation criticism vs Translation Theory}

As I mentioned above, translation and theory are both culture-bound. Starting from the ideas of the eminent authors of modern Turkish literature on Translation, I will try to explain not only why translation and translation theory are culture-bound, but also in what way theorizing translation evolve from translation criticism into translation theory. Within this framework I will quote what the eminent authors who launched intensive translation activity in the foundation years of Turkish Republic thought on translation to discuss whether we can assume what they thought on translation activity from the perspective of translation theory.

Translation has played a very great part in the foundation of Turkish written culture. Since the the courtly literature in the reign of the Ottomans addressed only to the royalty, literacy did not disseminate throughout the country. However, if we are to discuss this issue from the perspective of Republican Age, we have to study the perspectives of eminent authors and poets bearing dual identity as translators and authors. I can enlist Nurullah Ataç, Halide Edip or Nazım Hikmet as the leading actors laying the foundations of Modern Turkish Literature and translation activity in Turkey. Their discussion on translation concentrates on faithful or free translation in the beginning. The following statements of Nurullah Ataç, who was the representative of "inverted style" in Modern Turkish, expresses his ideas on translation as follows:

While translating, one should search for the equivalent of the sentence, not the words. Words do not express what the author intends to say, it is the whole when they combine with each other. (...) Man thinks not with words, but with sentences. ." [1989: 29)

On the other hand, Nazım Hikmet, one of the most remarkable poets of Modern Turkish Literature, wrote to Kemal Tahir, who was the most eminent novelist of Turkish literature, in his work Mapusaneden Mektuplar "Letters from Prison" defines translation as follows:

For example, the Russians use the term "my dove" as a word of love: however, we say "the light of my eye". According to me, when translating them, we should not say "my little one", similarly the Russians should not translate "the light of my eye" as "my dove" since it not used in Russian. While we introduce "my dove" to Turkish, they should introduce "the light of my eye to Russian. Languages enrich by exchanging such expressions, or attributes. Of course, there are things that cannot be translated, but they are not much" $(1975: 264)$. 
The common denominator between these two statements is the rationalization of their thoughts on translation based on their own translatorial experience they acquired in the course of translation. They can also be assumed as the selfdescription, or the think-aloud protocols of translators as Hans Hönig stated in studying mental stages of translators (1990: 82-85). However, their account of translation based on the principle of "equivalency" concerns their subjective views on translation. Therefore, we cannot acknowledge these statements as a theoretical ground open to debate and testability by other researchers. Theorization requires the conversion of subjective claims into a common framework open to public sphere; Although the above-mentioned critiques on translation starts discussion, they cannot be assumed as "theoretical" since they do not discuss translation at meta=level. If they had started the discussion from the concept of "equivalency" rather than the individual linguistic choices of the translators, we would conclude that they had transcended the borders of translation criticism. Then, we can mention that they were the Turkish pioneers of Translation Theory. That is to say, the subjective critiques of the above-mentioned authors on translation failed to proceed for theoretical debate. On the other hand, their critiques may serve as a corpus of study for time-limited research since they represent the translation norms concerning a specific culture in a certain period of time. Then, we can reach such a conclusion that "translation criticism" can evolve into "translation theory" only when retrospective data collected from the corpus leads to meta-level thinking, and yields prospective claims to search for. This will also inevitably maintain scholarly discussion in academic arena. Undoubtedly, it takes a long time to change the misconception of translation criticism as translation theory not only in Turkey, but also throughout the world. The debates on free or faithful translation seemed to last as a vicious circle, but once the barrier between them has been demolished, theorists achieved not only to prove the position of Translation Studies as a full-fledged autonomous discipline, but also as a competitive field of study open to multidisciplinary and transdisciplinary research.

Accordingly, I can enlist stages of theorization in the field of translation studies as follows:

1. Collecting data to for a corpus of study based on a specific problem such as loss, equivalency or next

2. Studying and identifying the regularities

3. Reaching findings

4. Explaining and discussing the relations at meta-level to trigger new claims

5. Finally, launching new research to verify or refute the past findings.

\section{Conclusion}

In the light of the discussion I have maintained so far, I draw up following conclusions concerning theorization in translation and translation theory:

1. Complexity and comparison are the defining features of both translation and theorization. Accordingly, the ultimate aim of both actions is solving the complexity. In fulfilling this action both translators and theorists undergo similar stages of logical sequencing such as abstraction, comparison classification, simplification, or explicitation. However, while the translator focuses on the task $\mathrm{s} / \mathrm{he}$ is commissioned to, $\mathrm{s} /$ he reasons or takes decisions within the borders of a text. Translator's ultimate aim is providing logical coherency within a single text. S/he may take different decisions in different texts in consideration for the textual conventions or translation norms peculiar to target culture. However, theorists work on a corpus, and aim to reach universals, or laws. Accordingly they aim to reach synthesis, which requires reasoning at meta-level.

2. Both theorists and translators start reasoning in target culture. However, while translators start and end in target culture, theorists ultimate destination is universal. That is to say, translators ultimate goal is to produce such a product as to fulfill a function in target culture. Whereas, the theorist first spots the complexity in target culture, defines and discusses it in target language so as to conceptualize the problem; finally, he aims to generalize it in such a way as to relate it to a universal problem.

3. The translator takes decisions alone in the course of translation. When he ends translation task, his responsibility ends. The reader appropriates the text, and uploads new functions according to her/his purpose. The goal or purpose of the text changes according to time, space or situation. However, theorization is open to debate to flourish. As long as the debate continues, the theorist can see multiple aspects of a problem, and construct a sound theoretical framework for further research. However, the translation criticism only serves for retrospective ends as opposed to the achievement oriented goals of theorization.

All in all, we cannot imagine translation without theorization, or theorization without translating; yet we should always consider the fuzzy border between translation, translation criticism and translation theory.

\section{References}

Ataç, N. (1940). Tercüme Üstüne, Günlerin Getirdiği. Istanbul: Can Yayınları. pp.128-135.

Chesterman, A. (1997). Memes of Translation: The spread of ideas in translation theory. Translation. Benjamins Translation Library.

Gile, D. (2003). Justifying the verbalization approach in the interpreting and translation approach. Forum 1:2.PP.4763.

Hikmet, V. T. (1989). Nazımla Söyleşi. Çev. Ataol Behramoğlu. İstanbul: Cem Yayınevi. 
Hönig, H. G. (1990). Holmes’ Mapping Theory and the Landscape of Mental Translation Processes, In: Kitty Leuven-

Zwart, M. V. \& Naaijkens T. (eds.). Translation Studies The State of Art. Proceedings of the First James. Holmes Symposium on Translation Studies, pp.77-89.

Kalverkämper, H. (1999) Translation swissenschaft als integrative Disziplin. In: Heidrun Gerzymisch-Arbogast, Gile, D., House, J., \& Rothkegel, A. (eds.). Wage der Übersetzungs- und Dolmetschforschung, Tübingen: Gunter Narr Yayınevi, pp.55-76.

Lefevere, A. (1992). Translation, Rewriting, and the Manipulation of Literary Fame. New York: Routledge.

Paker, S. (2002). Translation as Terceme and Nazire Culture-bound Concepts and their Implications for a Conceptual Framework on Ottoman Translation History. In: Theo Hermans (ed.). Crosscultural Transgressions: Research Models in Translation Studies II: Historical and Ideological Issues, Manchester: St. Jerome Publication, pp.120-143.

Pym, A. (2010). Exploring Translation Theories. New York: Routledge.

Stolze, R. (2011). The Development of Translation Studies as a Discipline - From Linguistic to Cognition. Translatio, [online] 1. Available at: http://seer.ufrgs.br/index.php/translatio/ article/view/36680/23747 [Accessed 19 Jan. 2015].

Salevsky, H. \& Ina, M. (2011). Translation as systemic Interaction. Frank \& Timme.

\section{Dictionaries}

Felsefe Terimleri Sözlüğü, 1975. Ankara:.TDK,

Türkçe Sözlük, 1988 Ankara.: TDK

Oxford Dictionary Available at:http://www.oxforddictionaries.com/ definition/english/translate [Accessed 19 Jan. 2015]. 